\title{
Enxerto ósseo esponjoso autólogo em pequenos animais
}

\author{
Autologous cancellous bone graft in small animals
}

Fernanda Carpi dos Santos ${ }^{1}$ Sheila Canevese Rahal $^{2}$

REVISÃO BIBLIOGRÁFICA

\section{RESUMO}

\begin{abstract}
O enxerto ósseo esponjoso autólogo é formado por osso trabecular, poroso e altamente celular. Visto ser de fundamental importância na cirurgia ortopédica de pequenos animais, o trabalho teve por objetivo discorrer sobre a função, locais de colheita, cuidados, formas de aplicação, indicações $e$ contra-indicações desse enxerto. Ele estimula a formação óssea devido ao fornecimento de células vivas e fatores de crescimento, mas não possui suporte mecânico. A asa do ílio craniodorsal, úmero proximal, tíbia proximal e fêmur distal, são os locais de colheita mais utilizados em cães. A asa do ílio consiste no local mais satisfatório para gatos. Para maximizar a incorporação do enxerto com o tecido hospedeiro, devem ser tomados alguns cuidados entre a colheita e a transferência para a área receptora. Além disso, pode ser aplicado sem compressão dentro do local recipiente. A freqüência de complicações é considerada baixa.
\end{abstract}

Palavras-chave: cirurgia, ortopedia, cães, gatos.

\section{ABSTRACT}

The autologous cancellous bone is formed by trabecular bone, porous, and highly cellular. Since this graft is very important in orthopedic surgery of small animals, the purpose of this paper is to describe the function, donor sites, precautions, application methods, indications, and contraindications. It stimulates the bone formation because it provides live cells and growth factors, but it did not have mechanical support. Cranial dorsal wing of the ilium, proximal humerus, proximal tibia, and distal femur are the most common harvest sites used in dogs. The wing of the ilium is the most satisfactory harvest site in cats. To maximize the graft incorporation with the tissue it is necessary to take care during the harvest and transference to recipient site. In addition, it may be put into the recipient site with no compression. The frequency of complications is considered low.

Key words: surgery, orthopedic, dogs, cats.

\section{INTRODUÇÃO}

Os enxertos ósseos são utilizados como adjuvantes no tratamento de fraturas, perdas e defeitos ósseos, e na indução de artrodeses (WEIGEL, 1993; JOHNSON, 1995). Diversos métodos e termos têm sido aplicados para classificar e descrever diferentes tipos e usos dos enxertos (WEIGEL, 1993).

Quanto à origem, eles são denominados: autólogos ou autógenos - transplantados de um local para outro no mesmo animal; homólogos ou aloenxertos - transplantados de um animal a outro da mesma espécie; heterólogos ou xenoenxertos - transplantados entre animais de espécies diferentes (PIERMATTEI \& FLO, 1997; MARTINEZ \& WALKER, 1999). Os auto-enxertos são histocompatíveis e não induzem à rejeição, diferente do observado com os aloenxertos e

\footnotetext{
${ }^{1}$ Médico Veterinário, Ex-Bolsista, Programa Institucional de Bolsas de Iniciação Científica, Conselho Nacional de Desenvolvimento Científico e Tecnológico. Residente (R1), Cirurgia de Pequenos Animais da Faculdade de Medicina Veterinária e Zootecnia (FMVZ), Universidade Estadual Paulista (UNESP), Botucatu.

${ }^{2}$ Médico Veterinário, Doutor, Professor Adjunto do Departamento de Cirurgia e Anestesiologia Veterinária da FMVZ, UNESP Botucatu, Rubião Júnior, s/n, 18618-000, Botucatu, SP. E-mail: sheilacr@fmvz.unesp. Autor para correspondência.
} 
xenoenxertos. Esses últimos, para serem utilizados, devem ter a antigenicidade diminuída por irradiação, congelamento, preservação química ou autoclavagem, entre outros tratamentos (JOHNSON, 1995).

Pela estrutura morfológica, os enxertos ósseos podem ser divididos em: esponjoso - formado por osso trabecular, poroso e altamente celular; cortical - constituído de osso compacto, denso e relativamente acelular; corticoesponjoso - composto de ambos os tipos, tais como costela ou asa do ílio (WEIGEL, 1993; JOHNSON, 1995). Há também os enxertos vascularizados que consistem na mobilização de um segmento ósseo com seu pedículo vascular, que deve ser anastomosado por técnica microvascular a artéria e veia próximas ao defeito (JOHNSON, 1995; PERRY, 1999).

Como o enxerto esponjoso é de fundamental importância, na cirurgia ortopédica, em pequenos animais, a revisão tem por objetivo discorrer sobre a função, locais de colheita, cuidados, formas de aplicação, indicações e contra-indicações desse enxerto.

\section{Funções}

Entre as funções do enxerto ósseo esponjoso incluem-se osteogênese, osteoindução e osteocondução (ALEXANDER, 1987; JOHNSON, 1991; FITCH et al., 1997; MARTINEZ \& WALKER, 1999).

A osteogênese consiste na formação de osso pelas células que sobreviveram à transferência (ALEXANDER, 1987; FITCH et al., 1997) e iniciase por volta de cinco dias após a transferência (MARTINEZ \& WALKER, 1999). O enxerto esponjoso tem grande potencial osteogênico por conter células quiescentes, células mesenquimais indiferenciadas e osteoblastos ativos (MARTINEZ \& WALKER, 1999). Estima-se que apenas 10\% das células deste tipo de enxerto sobrevivam à transferência (PIERMATTEI \& FLO, 1997).

O recrutamento e diferenciação de células mesenquimais indiferenciadas em osteoblastos é conhecido como osteoindução (JOHNSON, 1991; FITCH et al., 1997). A diferenciação é modulada por vários fatores, tais como a proteína morfogenética óssea, o fator de crescimento transformante beta, as citocinas, o fator de necrose tumoral e as prostaglandinas E2 (MARTINEZ \& WALKER, 1999). Além disso, faz-se necessário um ambiente favorável e um estímulo indutivo, como um fragmento ósseo ou célula osteogênica (ALEXANDER, 1987).

A osteocondução é um processo tridimensional de crescimento de capilares, tecido perivascular e células mesenquimais do leito recipiente para dentro da estrutura enxerto (MARTINEZ \& WALKER, 1999).

Locais de colheita

O enxerto esponjoso pode ser colhido da metáfise de qualquer osso longo, mas, pela facilidade técnica e volume, tem sido removido, em cães, na porção craniodorsal da asa ilíaca, úmero proximal, tíbia proximal e fêmur distal (JOHNSON, 1995; PIERMATTEI \& FLO, 1997; SLOCUM \& SLOCUM, 1998) (Figura 1). Em gatos, segundo DENNY \& BUTTERWORTH (2000), a colheita de enxerto do úmero proximal, fêmur ou tíbia pode ser frustrante, por serem obtidas pequenas quantidades, especialmente em adultos. A asa do ílio consiste no local mais satisfatório.

Há evidências de que osso de origem membranosa (ílio) é mais osteoindutivo que o de origem endocondral (tíbia e fêmur) (PERRY, 1999). O local de escolha deve ser determinado pelo volume necessário e proximidade do leito receptor (FOX, 1984). Em geral, apenas um local de colheita é suficiente para cães de tamanho grande ou médio; porém, em cães “toys” podem ser necessários diversos locais (SCHENA, 1983). PENWICK et al. (1991) observaram em estudo, com oito cães, que a restauração do enxerto esponjoso no local doador foi mais rápida e completa no úmero em relação à tíbia. Os resultados sugeriram ser o úmero fonte para uma segunda colheita de enxerto num período de dois meses, mas não a tíbia, que apresentou proeminente quantidade de tecido conjuntivo.

\section{Acessos cirúrgicos para colheita}

O acesso cirúrgico para a crista ilíaca, de acordo com SCHENA (1983), consiste em incisão de pele e tecido subcutâneo diretamente sobre aquela. O músculo glúteo, após a secção de sua origem fascial, é elevado e retraído ventralmente. Osteótomo e martelo ou pino de Steinmann ou trefina podem ser utilizados para criar abertura do córtex externo, evitando traumatizar o córtex medial, e o osso esponjoso é removido com cureta. Outra opção consiste em afastar os músculos glúteo médio e sacroespinhal, respectivamente das faces lateral e medial da crista ilíaca, remover uma cunha, ou criar um retalho da crista ilíaca com osteótomo e martelo, seguido de colheita com cureta do enxerto de dentro da asa do ílio (FOX, 1984; JOHNSON, 1991) (Figura 2). Esta última técnica é a preferida pelos autores da presente revisão, pela facilidade da colheita e grande quantidade de enxerto obtido. 


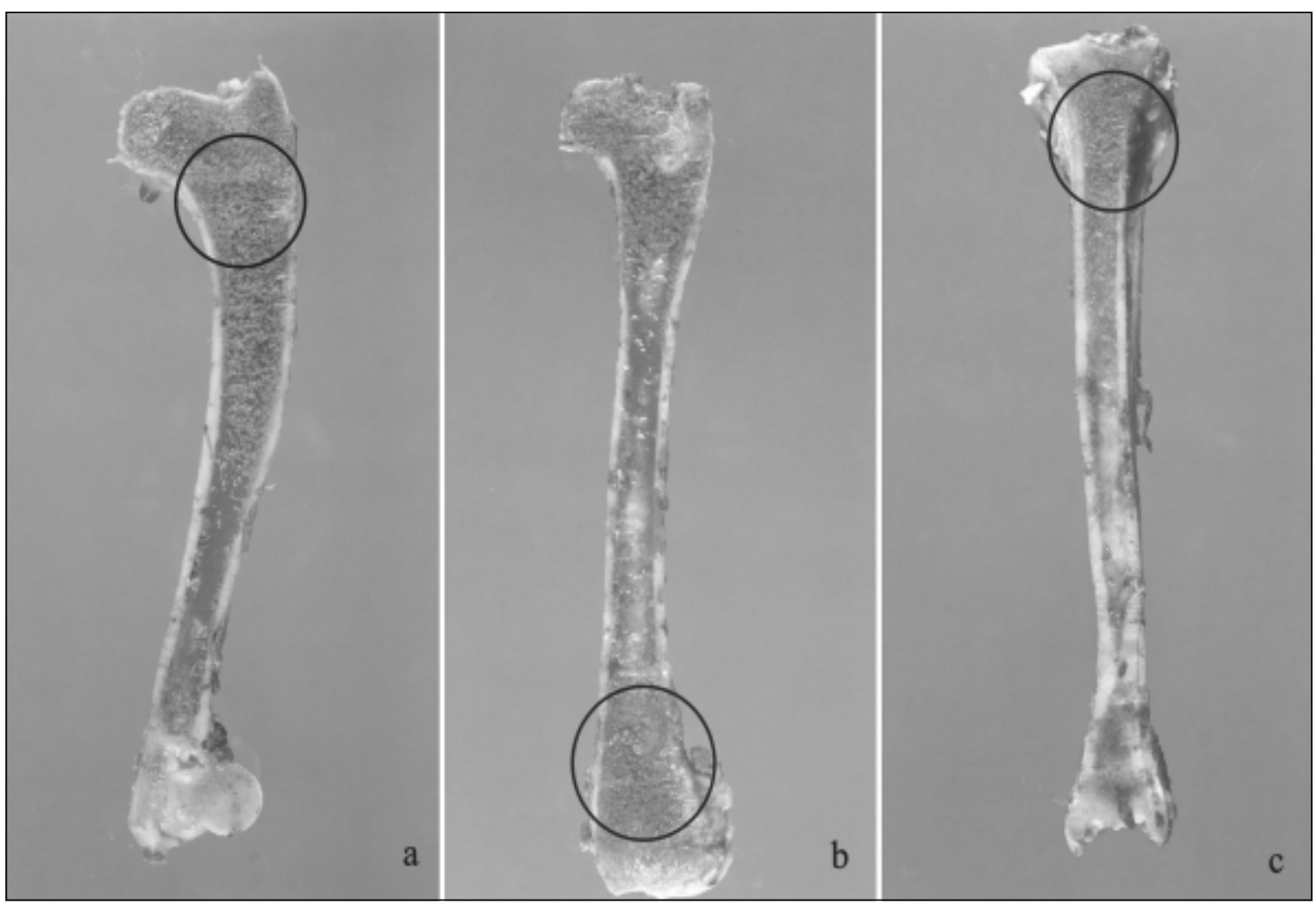

Figura 1 - Ossos do úmero (a), fêmur (b) e tíbia (c) de cães seccionados longitudinalmente para demonstrar os locais mais comuns de colheita do enxerto esponjoso.

Para a colheita de enxerto, no úmero proximal, realiza-se incisão craniolateral de pele e tecido subcutâneo (STEVENSON, 1990; JOHNSON \& HULSE, 2002). A porção acromial do músculo deltóide é afastada caudalmente expondo a metáfise proximal, o córtex ósseo é penetrado com pino Steinmann ou broca sulcada e o enxerto colhido com cureta óssea inserida e direcionada caudomedial (SCHENA, 1983; JOHNSON \& HULSE, 2002). O orifício deve ser proporcional ao diâmetro ósseo e de formato redondo ou elíptico para evitar fratura secundária à concentração de estresse (JOHNSON, 1991). Os tecidos são aproximados após hemostasia por compressão com gaze (SCHENA, 1983).

Na tíbia proximal medial, segundo FOX (1984), a pele deve ser incisada abaixo do platô tibial e entre o ligamento colateral e a tuberosidade tibial. O tecido subcutâneo e a inserção dos músculos sartório e grácil são separados por dissecação romba. O córtex pode ser perfurado com pino Steinmann, broca ou trépano, e o enxerto esponjoso colhido com cureta óssea. Cuidado deve ser tomado para não penetrar o córtex cranial ou lateral, visto ser a tíbia um osso com formato triangular (STEVENSON, 1990). A região é irrigada e os tecidos aproximados (FOX, 1984).

A colheita de enxerto no fêmur distal pode ser realizada, segundo SLOCUM \& SLOCUM, 1998), tanto pelo acesso medial como lateral. Efetua-se incisão da pele até a porção óssea, em torno de $1,5 \mathrm{~cm}$ de comprimento, centrada entre a fabela e a patela, tendo como limite distal da incisão o polo proximal da patela. Utilizando-se retrator de Gelpi, visualizase a córtex óssea na margem caudal da reflexão da cápsula articular, que deve ser perfurada com pino de Steinmann. Em cães, é possível colher, com o auxílio de cureta, aproximadamente $1 \mathrm{~cm}$ de enxerto para cada 4,5kg de peso corpóreo. Após a colheita, sutura-se o estrato sinovial para cobrir a perfuração e cessar a hemorragia, aproxima-se a fibrocartilagem parapatelar e posteriormente a pele.

Defeitos corticais ovais e bilaterais foram realizados, por TREVOR et al. (1992), na área subtrocantérica do fêmur de 16 cães, de onde o enxerto esponjoso foi removido e pesado. De forma similar, enxerto esponjoso foi colhido da porção proximal do úmero de sete desses cães. Embora a média de peso 

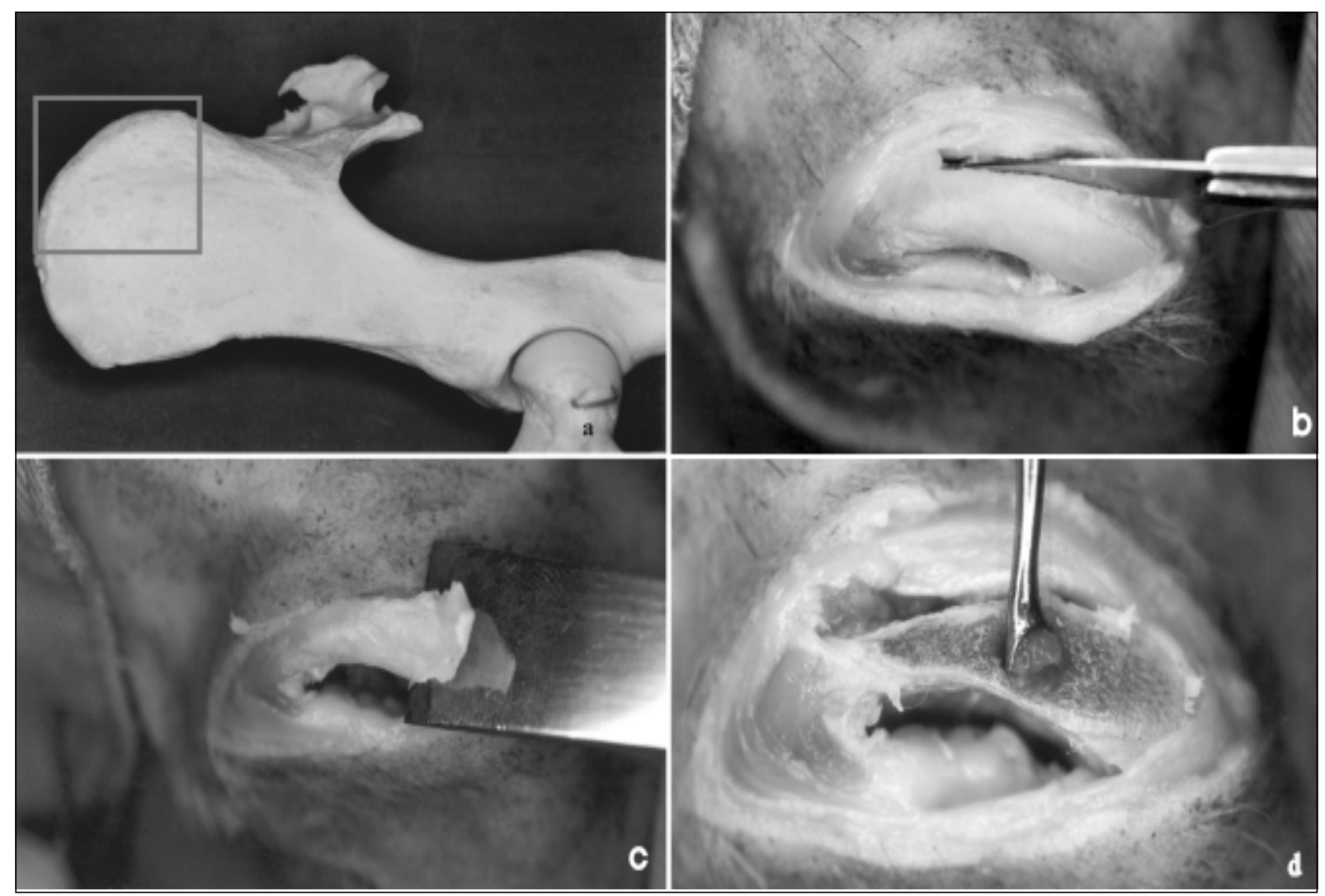

Figura 2 - Seqüência cirúrgica da colheita de enxerto esponjoso da região ílíaca. Vista lateral do osso coxal com delimitação do local para colheita de enxerto esponjoso (a). Afastamento dos músculos glúteo médio e sacroespinhal (b). Remoção de retalho da crista ilíaca com osteótomo e martelo (c). Colheita com cureta do enxerto de dentro da asa do ílio (d).

do enxerto colhido do fêmur tenha sido significantemente menor que a do úmero, não foram detectadas diferenças histológicas ou radiográficas na cicatrização em defeitos que foram tratados com esses enxertos. Segundo os autores, a porção proximal do fêmur pode ser usada para obter quantidades moderadas de enxerto e uma segunda colheita da mesma área pode ser feita após 12 semanas.

CULVENOR \& PARKER (1996)

observaram, em estudo com cadáveres de cães, que a quantidade de enxerto esponjoso obtida da asa do ílio, após remoção da crista dorsal e colheita com cureta óssea, foi inferior à quantidade de enxerto corticoesponjoso removida da secção côncava do ílio lateral usando raspa acetabular. Os autores concluíram ser este último método uma opção rápida e fácil de colheita de enxerto.

Ao compararem enxerto ósseo autólogo obtido do úmero com o corticoesponjoso colhido da asa do ílio com raspa acetabular, STALLINGS et al. (1997) verificaram, por exames histológicos e radiográficos, que ocorreu incorporação mais completa do primeiro, 35 dias após a implantação.

\section{Cuidados}

Para a colheita do enxerto, o cirurgião deve ser bastante cuidadoso com relação à assepsia (SCHENA, 1983). Além disso, deve evitar trauma aos tecidos e o uso de serras oscilatórias, que induzem aumento de temperatura no osso adjacente, resultando em morte celular e retardo na osteogênese (STEVENSON, 1990).

Após a colheita, o enxerto esponjoso autólogo deve ser aplicado o mais rapidamente possível (PIERMATTEI \& FLO, 1997). No entanto, se for necessária a estocagem até o momento da transferência para a área receptora, o enxerto pode ser mantido envolto em compressa de gaze umidecida com sangue ou colocado em uma cuba (Figura 3a) que deve ser coberta com gaze umidecida em solução salina 0,9\% ou Ringer (SCHENA, 1983; JOHNSON, 1995; PIERMATTEI \& FLO, 1997). Neste último, o enxerto pode ser mantido até 3 a 4 horas (STEVENSON, 1990). A exposição ao ar por 30 minutos ou mais diminui a viabilidade celular, e a elevação da temperatura acima de $42^{\circ} \mathrm{C}$, devido à

Ciência Rural, v. 34, n. 6, nov-dez, 2004. 

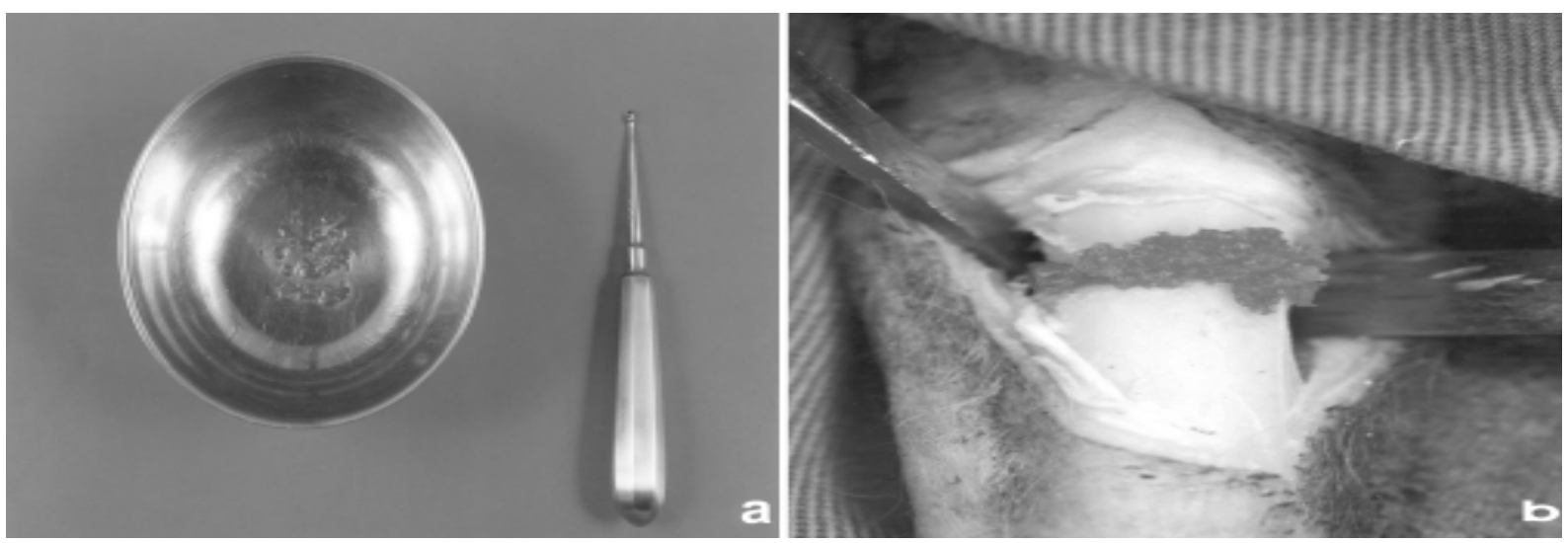

Figura 3 - Enxerto esponjoso autólogo mantido em cuba até a utilização. Para melhor proteção do enxerto, esta deve ser posteriormente coberta com gaze umidecida em solução isotônica (a). Aplicação de enxerto sem compressão junto ao foco de fratura (b).

luminosidade da sala cirúrgica, induz à morte celular (FOX, 1984). Sangue pode ser misturado ao enxerto colocado na cuba, uma vez que evita secagem e, após a coagulação, forma um composto moldável de fácil manipulação (JOHNSON, 1995). Um fato importante é que o enxerto não deve ser imerso em soluções isotônicas ou tratado com antibióticos (bacitracina, neomicina e kanamicina), por serem tóxicos para as células (FOX, 1984; JOHNSON, 1995; PIERMATTEI \& FLO, 1997).

McANULTY (1999) determinou o efeito de vários métodos de estocagem na viabilidade de fragmentos ósseos esponjosos obtidos de coelhos. A estocagem em $22^{\circ} \mathrm{C}$ por três horas em esponja umidecida com sangue ou solução salina isotônica permitiu viabilidade de $63,8 \%$ e $65,2 \%$, respectivamente. $\mathrm{O}$ uso de salina fria reduziu a viabilidade para 53,6\%; contudo, esta foi significativamente melhor para fragmentos estocados em soluções frias de EuroCollins (71,4\%) e sucrose tamponada com fosfato (70,4\%). Após reperfusão, a viabilidade foi maior para fragmentos estocados em sucrose tamponada (70,2\%) e EuroCollins (72,6\%) comparada com aqueles estocadas em salina fria $(47,6 \%)$ ou esponja umidecida com sangue $(57,2 \%)$.

O tamanho da partícula óssea tem importância na vascularização e sobrevivência da células do enxerto (WEGEL, 1993). Há evidências de que fragmentos menores que $0,7 \mathrm{~mm}$ não estimulam a osteogênese adequadamente e, se muito reduzidos, além de não formarem osso, induzem à resposta de granuloma por corpo estranho (FOX, 1984).

Antes da aplicação do enxerto, o local receptor deve ser lavado amplamente com salina isotônica para remover restos necróticos, fragmentos teciduais e coágulos sanguíneos, para facilitar a revascularização do enxerto e reduzir a incidência de infecção (SCHENA, 1983; JOHNSON, 1995; PIERMATTEI \& FLO, 1997).

Segundo EINHORN (1995), há um aumento da sobrevivência de células do enxerto quando são aplicadas em fraturas estáveis. Isso ocorre devido à rápida revascularização, permitindo um bom contato entre o leito receptor e o enxerto.

KERWIN et al. (2000) induziram defeitos, com potencial para não-união, na diáfise ulnar direita e esquerda, de 12 gatos adultos. Após 20 dias, um dos defeitos ósseos foi tratado com enxerto esponjoso autólogo colhido da porção proximal do úmero e seis gatos receberam oxigênio hiperbárico por 90 minutos, uma vez ao dia, por 14 dias. O uso de oxigênio hiperbárico não afetou a revascularização, aparência radiográfica ou histológica dos enxertos.

Formas de aplicação e incorporação

O enxerto deve se aplicado sem compressão dentro do local recipiente e mantido pela pressão dos tecidos moles circundantes (DENNY, 1985; ALEXANDER, 1987; JOHNSON, 1991) (Figura 3b). Para avaliarem se o enxerto esponjoso autólogo deve ser comprimido quando aplicado, MARTINEZ et al. (1992) produziram um defeito cortical no córtex caudal da porção proximal da ulna, em cinco cães adultos. Enxerto esponjoso foi colhido do tubérculo maior do úmero e aplicado no local recipiente, com ou sem compressão. Não foram detectadas diferenças na capacidade osteogênica entre os enxertos, tanto por análises histomorfométricas como pela densitometria óptica. 
Ao avaliarem o efeito osteogênico de diferentes volumes de enxerto esponjoso autólogo, colocados em defeitos corticais induzidos na ulna de quinze cães, DeVRIES et al. (1996) observaram que um preenchimento excessivo não aumenta o potencial osteogênico e um preenchimento parcial promove atraso. Desta forma, apenas o volume suficiente para preencher um defeito cortical é necessário para obter o máximo efeito osteogênico do osso transplantado.

De acordo com MILLIS \& MARTINEZ

(2003), há vários estádios de incorporação do enxerto autólogo esponjoso em um foco de fratura. Inicialmente forma-se um hematoma que gradualmente se organiza, sendo reabsorvido em uma a duas semanas. A resposta inflamatória ocorre em minutos ou horas. Com a revascularização e osteoindução, surgem alças capilares dentro de cinco dias. O tecido necrótico é reabsorvido, e o enxerto é totalmente revascularizado em 20 dias. A remodelação prossegue, com corticalização e medulização.

\section{Complicações}

Embora as complicações sejam consideradas de baixa freqüência, são citadas para o local doador, a formação de seroma, hemorragia, deiscência da ferida, fratura e contaminação por bactérias e células tumorais e, para o local receptor, a ausência de estímulo para formação óssea e não incorporação ao local da fratura (JOHNSON, 1991; DENNY \& BUTTERWORTH, 2000). Na experiência dos autores da presente revisão, a probabilidade de formação de seroma é maior na colheita de enxerto da porção craniodorsal do ílio em animais obesos. Portanto, nestes casos, a sutura de aproximação dos tecidos incisados deve ser precisa, para minimizar a formação de espaço morto.

Um cão de cinco meses de idade que apresentava encurtamento do rádio e subluxação da articulação do cotovelo foi tratado, por PALMISANO \& SCHRADER (1999), com osteotomia do rádio e aplicação de enxerto esponjoso colhido do úmero. Após quatro meses do procedimento cirúrgico, o cão voltou a claudicar e foi detectado fechamento prematuro da placa de crescimento proximal do úmero. Segundo os autores, para evitar esse tipo de complicação, o enxerto em animais imaturos deve ser colhido da asa do ílio e não em locais em que a placa de crescimento possa ser lesada.

FERGUSON (1996) relatou o caso de um cão, cinco anos de idade, que desenvolveu uma fratura do úmero após colheita de enxerto esponjoso. A causa da lesão foi associada ao direcionamento e posicionamento do orifício de colheita além do nível do tubérculo maior. Segundo o autor, para criar um orifício circular, a broca deve ser dirigida perpendicular ao córtex e não obliquamente.

Enxerto esponjoso autólogo foi colhido, por JOHNSON (1986), da metáfise proximal de 30 cães de porte médio e grande. As complicações observadas foram uma fratura incompleta do córtex tibial, ocorrida durante a curetagem do osso metafiseal, e três casos de deiscência da ferida precedida pela formação de seroma.

Indicações e desvantagens

Entre as indicações do enxerto esponjoso estão: o auxílio à consolidação de fraturas, tanto as primárias como as retardadas ou não-uniões; no preenchimento de defeitos corticais que se seguem à curetagem ou excisão de um cisto ósseo ou tumor; nas perdas ósseas segmentares traumáticas; no tratamento de osteomielites; como auxílio nos procedimentos de artrodese articulares; na fusão vertebral; em associação com enxerto cortical (SCHENA, 1983; FOX, 1984; ALEXANDER, 1987; DENNY \& BUTTERWORTH, 2000). Além disso, apresenta vantagens como histocompatibilidade e rápida incorporação sem risco de transmissão de doenças (MARTINEZ \& WALKER, 1999).

Entre as desvantagens, estão o aumento no tempo cirúrgico, hemorragia ou desconforto do local doador, risco de infecção, volume limitado, falta de suporte biomecânico (SCHENA, 1983; FITCH et al., 1997; MARTINEZ \& WALKER, 1999).

\section{CONSIDERAÇÕES FINAIS}

Os enxertos autólogos esponjosos estimulam a formação óssea devido ao fornecimento de células vivas e fatores de crescimento, mas não possuem estrutura mecânica. A asa do ílio, úmero proximal, tíbia proximal e fêmur distal, são os locais de colheita mais utilizados em cães. A asa do ílio consiste no local mais satisfatório para gatos. Esses enxertos podem ser utilizados em diversos procedimentos ortopédicos, mas, para maximizar a incorporação com o tecido hospedeiro, devem ser tomados cuidados durante a colheita e aplicação.

\section{REFERÊNCIAS BIBLIOGRÁFICAS}

ALEXANDER, J.W. Bone grafting. Vet Clin North Am Small Anim Pract, Philadelphia, v.17, n.4, p.811-819, 1987.

CULVENOR, J.A.; PARKER, R.J. Collection of corticocancellous bone graft from ilium of the dog using an acetabular reamer. J Small Anim Pract, London, v.37, p.513-575, 1996. 
DENNY, H.R. Bone grafts in small animal orthopaedics. Vet Annu, Bristol, v.25, p.254-262, 1985.

DENNY, H.R.; BUTTERWORTH, S.J. Bone grafts. In:_-___. A guide to canine and feline orthopaedic surgery. 4.ed. London : Blackwell, 2000. Cap.2, p.18-23.

DeVRIES, W.J. et al. Effect of volume variations on osteogenic capabilities of autogenous cancellous bone graft in dog. Am J Vet Res, Schaumburg, v.57, n.10, p.1501-1505, 1996.

EINHORN, T.A. Current concepts review enhancement of fracture-healing. J Bone Joint Surg, Boston, v.77-A, n.6, p.940956, 1995.

FERGUSON, J.F. Fracture of the humerus after cancellous bone graft harvesting in a dog. J Small Anim Pract, London, v.37, p.232-234, 1996.

FITCH, R. et al. Bone autografts and allografts in dogs. Compend Cont Educ Pract Vet, Princeton Junction, v.19, n.5, p.558-576, 1997.

FOX, S.M. Cancellous bone grafting in the dog: An overview. J Am Anim Hosp Assoc, Golden, v.20, p.840-848, 1984.

JOHNSON, A.L.; HULSE, D.A. Fundamentals of orthopedic surgery and fracture management. In: FOSSUM, T.W. Small animal surgery. 2.ed. St. Louis : Mosby, 2002. Cap.33, p.848853.

JOHNSON, A.L. Bone grafting. In: OLMSTEAD, M.L. Small animal orthopedics. St. Louis: Mosby, 1995. p.146-151.

JOHNSON, A.L. Principles of bone grafting. Semin Vet Med Surg Small Anim, Philadelphia, v.6, n.1, p.90-99, 1991.

JOHNSON, K.A. Cancellous bone graft collection from the tibia in dogs. Vet Surg, Hagerstown, v.15, n.4, p.334-338, 1986.

KERWIN, S.C. et al. Effect of hyperbaric oxygen treatment on incorporation of an autogenous cancellous bone graft in a nonunion diaphyseal ulnar defect in cats. Am J Vet Res, Schaumburg, v.61, n.6, p.691-697, 2000.

MARTINEZ, S.A.; WALKER, T. Bone grafts. Vet Clin North Am Small Anim Pract, Philadelphia, v.29, n.5, p.1207-1219, 1999.

MARTINEZ, S.A. et al. Effects of a fixed compression load on the osteogenic effect of autogenous cancellous bone grafts in dogs. Am J Vet Res, Schaumburg, v.53, n.12, p.2381-2385, 1992.
MILLIS, D.L.; MARTINEZ, S.A. Bone grafts. In: SLATTTER, D. Textbook of small animal surgery. 3.ed. Philadelphia : Saunders, 2003. Cap.133, p.1875-1891.

McANULTY, J.F. Effect of various short-term storage methods on viability of cancellous bone fragments. Am J Vet Res, Schaumburg, v.60, n.1, p.63-67, 1999.

PALMISANO, M.P.; SCHRADER, S.C. Premature closure of the proximal physis of the humerus in a dog as a result of harvesting a cancellous bone graft. J Am Vet Med Assoc, Schaumburg, v.215, n.10, p.1460-1462, 1999.

PERRY, C.R. Bone repair techniques, bone graft, and bone graft substitutes. Clin Orthop, Philadelphia, v.360, p.71-86, 1999.

PENWICK, R.C.; MOSIER, D.A.; CLARK, D.M. Healing of canine autogenous cancellous bone graft donor sites. Vet Surg, Hagerstown, v.20, n.4, p.229-234, 1991.

PIERMATTEI, D.L.; FLO, G.L. Bone grafting. In:__. Small animal orthopedics and fracture repair. 3.ed. Philadelphia : Saunders, 1997. Cap.3, p.147-153.

SCHENA III, C.J. The procurement of cancellous bone for grafting in small animal orthopedic surgery: a review of instrumentation, technique, and pathophysiology. J Am Anim Hosp Assoc, Golden, v.19, p.695-701, 1983.

SLOCUM, B.; SLOCUM, T.D. Bone graft harvest: distal femoral condyles. In: BOJRAB, M.J.; ELLISON, G.W.; SLOCUM, B. Current techniques in small animal surgery. 4.ed. Baltimore : Williams \& Wilkins, 1998. p.909-910.

STALLINGS, J.T. et al. A comparison of autogenous corticocancellous bone graft obtained from the wing of the ilium with an acetabular reamer to autogenous cancellous bone graft obtained from the proximal humerus in dog. Vet Comp Orthop Traumol, Stuttgart, v.10, p.79-87, 1997.

STEVENSON, S. Bone grafting. In: BOJRAB, M.J.; BIRCHARD, S.J.; TOMLINSON, J.L. Current techniques in small animal surgery. 3.ed. Philadelphia : Lea \& Febiger, 1990. Cap.3, p.836-844.

TREVOR, P.B. et al. Evaluation of the proximal portion of the femur as an autogenous cancellous bone donor site in dogs. Am J Vet Res, Schaumburg, v.53, n.9, p.1599-1603, 1992.

WEIGEL, J.P. Bone grafting. In: BOJRAB, M.J.; SMEAK, D.D.; BLOOMBERG, M.S. Disease mechanisms in small animal surgery. 2.ed. Philadelphia : Lea \& Febiger, 1993. Cap.98, p.678-684. 